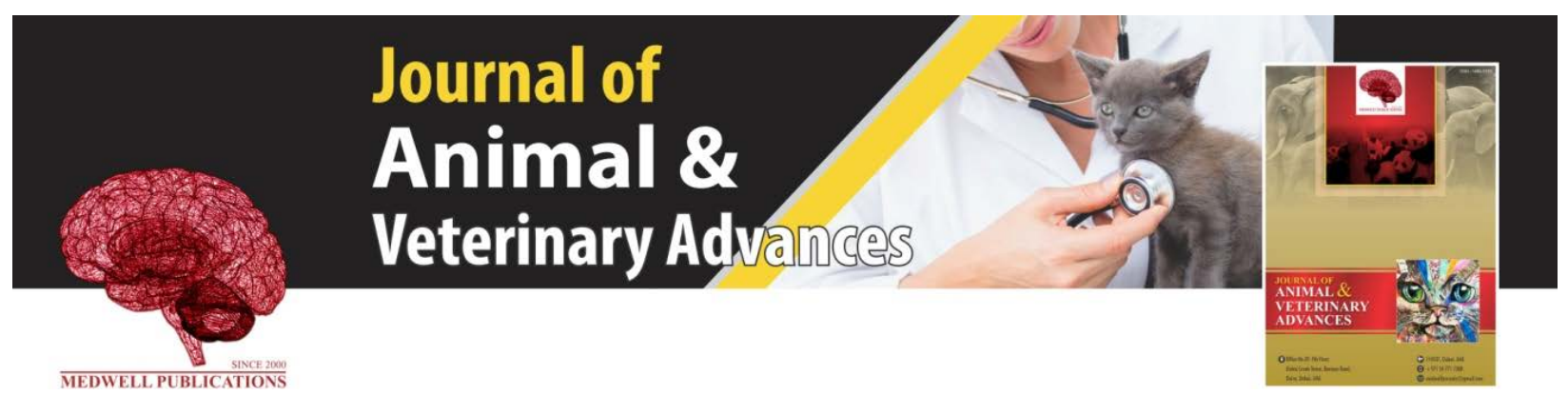

\title{
Characterization of Coagulase Negative Staphylococci Isolated from Dairy Goats in Germany
}

\author{
${ }^{1}$ A. Ehrenberg, ${ }^{2}$ A. Sobiraj, ${ }^{3}$ Castañeda-Vazquez, ${ }^{1,4}$ A. El-Sayed, ${ }^{3}$ M.A. Castañeda Vazquez and ${ }^{1}$ M. Zschöck \\ ${ }^{1}$ Landesbetrieb Hessisches Landeslabor, Schubertstrasse 6, D-35396 Gießen, Germany \\ ${ }^{2}$ Faculty of Veterinary Medicine, Department of Internal Medicine and Infectious Diseases, Ambulatory and \\ Bstetric Veterinary Clinic, Leipzig University, Leipzig, Germany \\ ${ }^{3}$ Laboratory of Mastitis and Molecular Diagnostic, Division of Veterinary Sciences, University of \\ Guadalajara, Guadalajara, Mexico \\ ${ }^{4}$ Faculty of Veterinary Medicine, Department of Internal Medicine and Infectious Diseases, Giza Square, \\ Cairo University, El Cairo, Egypt
}

Key words: NAS, coagulase negative Staphylococci, Germany, goat, subclinical mastitis, transfer DNA intergenic spacer length polymorphism PCR

\section{Corresponding Author:}

Castañeda-Vazquez

Laboratory of Mastitis and Molecular Diagnostic, Division of Veterinary Sciences, University of Guadalajara, Guadalajara, Mexico

Page No.: 1-10

Volume: 19, Issue 1, 2020

ISSN: 1680-5593

Journal of Animal and Veterinary Advances

Copy Right: Medwell Publications
Abstract: Over 2 years as a part of a surveillance program, 2038 one half milk samples were collected from dairy goats representing 12 German herds. Microbiological investigation of the samples revealed positive bacterial growth in $17.3 \%$ of them. Biochemical identification of the field isolates detected Non-Aureus Staphylococci (NAS) in $10.4 \%$, Corynebacteria in $3.2 \%$, Streptococci in $0.8 \%$, S. aureus in $0.7 \%$, other bacteria in $1.0 \%$. Meanwhile, mixed bacterial growth was shown in $2.2 \%$ of the samples. To identify the NAS isolates at their species level the detection of their biochemical properties alone using a commercial test kit enabled the correct identification of a randomized selection of the field isolates only in $11.4 \%$. For further identification, a combination of two other identification techniques (antibiotic resistance profiles and molecular assays) was additionally applied. By doing so, it was possible to identify 69 (58.5\%) out of 118 isolated presumptive NAS field strains at their species level. The detected species included S. caprae, S. epidermidis, S. simulans, S. hyicus, S. saprophyticus, S. chromogenes, S. lentus, S. xylosus and S. hominis. Among them, S. caprae was detected most frequently while $S$. lentus, S. xylosus and $S$. hominis were isolated only from sporadic cases.

\section{INTRODUCTION}

Mastitis is the most costly field problem in dairy industry. Although, the inflammation of the udder tissue is accompanied by the elevation of Somatic Cell Count $(\mathrm{SCC})^{[1]}$, the SCC in goat milk is normally much higher than in cattle milk which may lead to false diagnosis ${ }^{[2]}$. So that, goat milk is considered to be obtained from mastitis udder only if the SCC exceeds $1 \times 10^{6}$ cells per mL. However, results obtained by California Mastitis Test (CMT) should be supported by bacteriological examination as the SCC can be physiologically increased in late lactation, old ages and in low milk producers $^{[3,4]}$. 
In the last years, NAS turned into emerging mastitis pathogens. They replaced the coagulase positive ones (S. aureus) in most countries and became the most commonly isolated bacteria from mastitic milk ${ }^{[5]}$. Recently and due to the detection of some coagulase variable Staphylococcal species, the classification of Staphylococci into coagulase positive S. aureus and Coagulase Negative $S$. aureus (CNS) was changed into S. aureus and Non-Aureus Staphylococci (NAS) ${ }^{[6,7]}$. So that, in the present work, the term NAS will be used for the traditionally used CNS expression.

The prevalence of NAS in goat milk samples suffering from mastitis ranges between 25-95.9\% in subclinical form of the disease $\mathrm{e}^{[3,8]}$ and may even reach $100 \%$ of the samples of the clinical cases in certain locations ${ }^{[9]}$.

The NAS represent about 50.2-54.2\% of grown colonies cultured from normal goat milk compared to $41.5 \%$ for $S$. aureus. While the $S$. aureus is responsible mainly for the induction of clinical mastitis in goats, the NAS induces subclinical mastitis in most cases. The infection with NAS usually results in subclinical mastitis which can persist during the dry period and leads to the reduction of milk production with about $5.7 \%$ in infected goats $^{[3-5,10]}$.

Infection with NAS lead to the increase of SCC in the infected half compared with the healthy one. However, this increase remains less obvious than that caused by $S$. aureus infections ${ }^{[11-13]}$. This may be attributed to the lower pathogenicity of NAS compared with S. aureus, although, they can produce potent virulence factors, e.g., thermo-stable enterotoxins ${ }^{[4]}$.

In literature, different NAS species are known to induce mastitis in goats including $S$. saprophyticus, $S$. lentus, S. simulans, S. xylosus, S. haemolyticus, S. warneri $^{[4]}$, S. lugdunensis, S. hominis ${ }^{[14]}$, S. arlattae $S$. fleurettii, S. nepalensis, S. pasteuri, S. sciuri, $S$. gallinarum, S. equorum ${ }^{[5]}$ S. caprae $^{[12]}$, S. capitis $^{[4]}, S$. auricularis $^{[15]}$, S. cohnii ${ }^{[16]}$, S. muscae, S. vitulinus ${ }^{[8,16]}, S$. epidermidis, S. chromogenes, S. warneri and S. sciuri ${ }^{[17]}$.

At the time, few epidemiological investigations concerning the role of NAS in the induction of mastitis are available $\mathrm{e}^{[5]}$. The available so far published data showed that the prevalence of different NAS species varies greatly and seem to depend on the region studied. However, S. caprae, S. xylosus and to less extend $S$. equorum remain among the most detectable species in most publications ${ }^{[18,16]}$.

Due to the growing importance of NAS in the dairy sector and also due to their public health importance, it is necessary to differentiate among the NAS at their species level. While most researchers prefer to use the commercial kits for biochemical identification of Staphylococci $\left.{ }^{[19-21,} 4\right]$, others depended on the characteristic antibiotic profile of every species ${ }^{[22]}$. Recently, various molecular tools were applied for this purpose $^{[23]}$.
The aim of the present work is to evaluate the epidemiological role of various species of Non-Aureus Staphylococci (NAS) isolated from subclinical mastitic milk samples from goats in Hessia state, Germany using different identification assays. Farther the diagnostic meaningfulness of the different above mentioned methods should be clarified comparatively.

\section{MATERIALS AND METHODS}

Over 2 years, 2038 one half milk samples were collected from mastiticdairy goats in 12 German herds in Hessia state under antiseptic conditions. The Somatic Cell Count (SCC) was measured only in milk samples which were apparently normal and did not show any macroscopic abnormalities using Fossomatic ${ }^{\circledR} 360$ (Foss Electric A/S, Denmark).

For the characterization of the present pathogens in the milk, different identification tools were applied. These included bacteriological examinations, molecular identification (PCR), biochemical identification (ID32 Staph Test) and the use of their antibiotic resistance profile as a diagnostic guide as shown later.

Bacteriological examinations were carried out where all the samples were cultured on blood agar and esculin blood agar (Merck, Darmstadt, Germany) at $37^{\circ} \mathrm{C}$ overnight. Only NAS field isolates from samples with medium (++/i.e., 6-15 colonies) or strong bacterial growth $(+++$ i.e., more than 16 colonies) in pure culture (without mixed infections) were selected for further investigation.

Macroscopically suspected grown colonies were stained with gram stain and examined microscopically and were subjected to catalase and $\mathrm{KOH}$ test ${ }^{[24]}$.

The colonies were then tested in plasma coagulase and clumping factor test to differentiate among coagulase positive and coagulase negative staphylococci according to the methods described in the manual of clinical microbiology by Kloos and Bannerman. Only one colony per sample was randomly picked, fresh sub-cultured in tryptone soya broth and was then frozen in $10 \%$ glycerol until being used.

The reference strains $(n=17)$ used in the present work included S. auricularis (ATCC 33753), S. capitis (ATCC 27841), S. caprae (CCM 3573), S. chromogenes (ICM 7470), S. cohnii (GH 137), S. epidermidis (ATCC 14990), S. haemolyticus (ATCC 29970), S. hominis subsp. hominis (ATCC 27845), S. hyicus (ATCC 11249), S. lentus (ATCC 49574), S. lugdunensis (ATCC 43809), S. saprophyticus (ATCC 43867), S. schleiferisub sp. schleiferi (ATCC 43808), S. sciuri (ATCC 29062), S. simulans (ATCC 27848), S. warneri (ATCC 27836) and $S$. xylosus (Kloos 162).

Biochemical identification of the isolates was performed using the ID32 staph test. The assay aims to identify various staphylococci on the base of their biochemical reactions. The ID32 staph test (BioMérieux, 
Nürtingen) includes 26 wells containing dried substrates representing 26 colorimetric biochemical tests (urease, esculin hydrolyse, nitrat reduction, aceton formation, alkaline phosphatase, arginine arylamidase, arginine dihydrolase, ß-galactosidase, ß-glucuronidase, ornithinde decarboxylase, pyrridonyl-arylamidase, novobiocin resistence, acid production from arabinose, cellobiose, fructose, glucose, lactose, maltose, mannitol, mannose, raffinose, ribose, saccharose, trehalose, turanose and n-acetyl-glucosamine).

For biochemical identification of the 17 reference strains as well as a randomized selection of the the field isolates $(n=35)$ all tests were performed according to the manufacturer recommendation. For evaluation of the results the APILAB ID 32 computer Software was used.

Molecular identification of the isolates was done using the transfer DNA Intergenic spacer length polymorphism PCR (tDNA-ILP PCR assay). The assay was carried out for differentiation among various NAS species according to the method described by Maes et al. ${ }^{[25,26]}$.

The NAS isolates were fresh cultured to extract their genomic DNA according to Reinoso et al. ${ }^{[27]}$. The extracted DNA was used as template for the PCR assay using the primer pair T5A (59-AGTCCGGTGCTCTAAC CAACTGAG) and T3B (59-AGGTCGCGGGTTCGA ATCC) and the amplification program $\left(94^{\circ} \mathrm{C} \times 30 \mathrm{sec} \times 1\right.$, followed by 40 cycles of $50^{\circ} \mathrm{C} \times 30 \mathrm{sec}, 72^{\circ} \mathrm{C} \times 120 \mathrm{sec}$.

The obtained amplicons were separated by $1.5 \%$ agarose electrophoresis (Biorad, Germany). The gels were evaluated with the aid of the VIII marker (0.019-1.11 kbp, Boehringer Mannheim, Germany) and the Gel Documentation systems Gel Doc 1000 (Biorad, Germany).

The antibiotic resistance profiles of the reference strains $(\mathrm{n}=17)$ and the NAS field isolates against novobiocin, desferioxamin, fosfomycin, polymyxin B and furazolidon were performed according to Ehrenberg. In brief, fresh sub-cultured NAS colonies $(n=3-5)$ were picked and inoculated into tryptone soya broth. The broth was cultured at $37^{\circ} \mathrm{C}$ for approximately 2-3 h (until reaching a density of the 0.5 McFarland-standard). About $0.1 \mathrm{~mL}$ of the suspension was swabbed over the Mueller-Hinton agar plates. The remaining suspension was withdrawn from the plates. The antibiotic discs (Novobiocin $30 \mu \mathrm{g}$, Desferioxamin $1000 \mu \mathrm{g}$, Fosfomycin $50 \mu \mathrm{g}$, Polymyxin B $300 \mathrm{iU}$ and Furazolidon $50 \mu \mathrm{g}$; Oxoid, (UK) were then located with the disc dispenser (Oxoid, UK). The plates were re-incubated overnight at $37^{\circ} \mathrm{C}$. The antibiotic resistance profiles could be identified by measuring the diameter of the growth inhibition zones. The assumed borderline limits between sensitive and resistant were $16 \mathrm{~mm}$ for novobiocin, $18 \mathrm{~mm}$ for desferioxamin, $30 \mathrm{~mm}$ for fosfomycin, $12 \mathrm{~mm}$ for polymyxin B and $17 \mathrm{~mm}$ for furazolidon ${ }^{[28,29]}$.

\section{RESULTS AND DISCUSSION}

In the present study, 2038 one half milk samples were investigated. Out of these, 2029 milk samples (99.6\%) were apparently normal and did not show any visual abnormalities clots. Only 9 (0.4\%) samples showed macroscopically visible changes like divergences in consistency or blood in the milk that might indicate a clinical mastitis.

The Somatic Cell Count (SCC) was measured in apparently normal milk samples. The geometric mean of SCC per mL was 765.000 in samples from which S. aureus was isolated, 559.000 in case of esculin positive Streptococci, 301.000 in case of NAS and 298.000 in case of Corynebacterium spp.

All the samples were cultured overnight on blood agar, only $17.3 \%(n=353)$ of the total samples showed bacterial growth. The identification of the grown bacteria revealed NAS in 10.4\% $(\mathrm{n}=211)$, Corynebacterium spp. in $3.2 \%$ ( $\mathrm{n}=65)$, esculin positive Streptococci in $0.8 \%$ $(\mathrm{n}=16)$, S. aureus in $0.7 \%(\mathrm{n}=15)$ and finally, other bacteria in $1.0 \%(n=20)$ of the samples. In the same time, $1.3 \%(n=26)$ of the samples showed mixed growth of different bacteria, therefore were excluded from the evaluation.

Out of the 211 samples which reveald NAS in pure culture only 118 colonies (originating from 118 samples) met the requirements to be selected for further investigation (namely: milk-sample with elevated cell count or macroscopically visible changes, bacterial growth of NAS confirmed colonies with medium or strong bacterial growth).

For biochemical identification of the NAS isolates, the grown colonies were tested by ID32 staph test. The obtained results enabled the correct identification only of $11(64.7 \%)$ of the ATCC-reference strains and in only $4(11.4 \%)$ of the 35 randomely selected NAS field isolates for the performance of complete biochemical identification.

The sensitivity against the antibiotics novobiocin, desferioxamin, fosfomycin, polymyxin $B$ and furazolidon is used as an indicator for the differentiation among various NAS strains. Although, the resistance profile of the 17 reference strains revealed the expected profile described in the literature, only 93(78,8\%) out of the 118 investigated strains revealed a resistance profile similar to the reference strains.

The remaining 25 field isolates presented 6 new resistant profiles which could not be interpreted based on the available data (Table 1). Two of these profiles representing 5 NAS isolates contained a furazolidoneresistance. These field strains were proved to be Micrococci and were henceforward excluded from the study.

In the present work, the application of tDNA-ILP PCR assay was used to cluster the obtained genomic 
J. Anim. Vet. Adv., 19 (1): 1-10, 2020

Table 1: Antibiotic resistance profiles obtained by the examination of NAS isolates in the present work

\begin{tabular}{|c|c|c|c|c|c|c|c|c|}
\hline Profile No. ${ }^{1}$ & $\begin{array}{l}\text { Species (reference } \\
\text { strains) }\end{array}$ & Novo-biocin & Desferi-oxamin & Fosfo-mycin & Poly-myxin B & Furazo-lidon & n (field-isolates) & $\begin{array}{c}\text { Field } \\
\text { isolates (\%) } \\
\end{array}$ \\
\hline $\mathrm{R} 1$ & $\begin{array}{l}\text { S. auricularis, } \\
\text { S. capitis, } \\
\text { S. caprae, } \\
\text { S. hämolyticus, } \\
\text { S. warneri }\end{array}$ & $\mathrm{S}$ & $\mathrm{R}$ & $\mathrm{R}$ & $\mathrm{S}$ & $\mathrm{S}$ & 34 & 28.8 \\
\hline R2 & $\begin{array}{l}\text { S. chromogenes, } \\
\text { S. hyicus, } \\
\text { S. lugdunensis, } \\
\text { S. simulans, } \\
\text { S. schleiferi }\end{array}$ & S & $\mathrm{R}$ & S & S & S & 34 & 28.8 \\
\hline R3 & $\begin{array}{l}\text { S. cohnii, } \\
\text { S. lentus }\end{array}$ & $\mathrm{R}$ & $\mathrm{R}$ & S & $\mathrm{S}$ & $\mathrm{S}$ & 5 & 4.2 \\
\hline R4 & $\begin{array}{l}\text { S. saprophyticus, } \\
\text { S. sciuri }\end{array}$ & $\mathrm{R}$ & $\mathrm{R}$ & $\mathrm{R}$ & $\mathrm{S}$ & S & 7 & 5.9 \\
\hline R5 & S. epidermidis & $\mathrm{S}$ & $\mathrm{S}$ & $\mathrm{S}$ & $\mathrm{S}$ & S & 10 & 8.5 \\
\hline R6 & S. hominis & S & $\mathrm{S}$ & $\mathrm{R}$ & $\mathrm{S}$ & $\mathrm{S}$ & 2 & 1.7 \\
\hline R7 & S. xylosus & $\mathrm{R}$ & $\mathrm{R}$ & $\mathrm{S}$ & $\mathrm{R}$ & $\mathrm{S}$ & 1 & 0.8 \\
\hline R8 & & $\mathrm{S}$ & $\mathrm{R}$ & $\mathrm{R}$ & $\mathrm{R}$ & $\mathrm{S}$ & 9 & 7.6 \\
\hline R9 & & $\mathrm{S}$ & $\mathrm{R}$ & $\mathrm{S}$ & $\mathrm{R}$ & S & 8 & 6.8 \\
\hline R10 & & $\mathrm{S}$ & $\mathrm{R}$ & $\mathrm{S}$ & $\mathrm{S}$ & $\mathrm{R}^{2)}$ & 4 & 3.4 \\
\hline R11 & & $\mathrm{R}$ & $\mathrm{R}$ & $\mathrm{R}$ & $\mathrm{R}$ & S & 2 & 1.7 \\
\hline R12 & & S & $\mathrm{S}$ & $\mathrm{R}$ & $\mathrm{R}$ & S & 1 & 0.8 \\
\hline R13 & & E & $\mathrm{R}$ & $\mathrm{R}$ & $\mathrm{E}$ & $\mathrm{R}^{2)}$ & 1 & 0.8 \\
\hline
\end{tabular}

${ }^{11}$ The profiles R1-R7 were recorded in control strains while R1-R13 were recorded only in investigated strains; ${ }^{2)}$ Five isolates were addressed to be Micrococci and were excluded from further studies as they showed furazolidon-resistance

Table 2: Investigation of reference strains and field isolates with tDNA-ILP PCR assay

\begin{tabular}{llcc}
\hline PCR profile & Reference strain & Field strains (n) & Field strains (\%) \\
\hline A1 & S. chromogenes, S. hyicus S. epidermidis, S. saprophyticus, S. xylosus & 45 & $39.8 \%$ \\
A2 & S. caprae, S. simulans & 37 & $32.7 \%$ \\
A3 & S. lentus, S. sciuri & 2 & $1.8 \%$ \\
A4 & S. auricularis, S. lugdunensis & 0 & 0 \\
A5 & S. hominis & 1 & $0.9 \%$ \\
A6 & S. capitis & 0 & 0 \\
A7 & S. haemolyticus & 0 & 0 \\
A8 & S. warneri & 0 & 0 \\
A9 & S. cohnii & 0 & 0 \\
A10 & S. schleiferi & 0 & 0 \\
A11-A37 & - & 28 & $24.8(0.9 \%$ each)
\end{tabular}

${ }^{11}$ Total number of investigated field isolates is 113 as 5 of the isolates reacted negatively with the PCR

fingerprints in order to identify the 17 reference strains. The assay enabled to a large extend the identification of 10 of them based on their genomic profiles (Table 2, Fig. 1). The obtained 10 profiles were nummerated from A1-A10, namely: the closely related S. chromogenes, S. hyicus, S. epidermidis, S. saprophyticus and S. xylosus shared the same profile (A1), S. caprae and S. simulans (A2), S. lentus and S. sciuri (A3) and S. auricularis and S. lugdunensis (A4). The profiles from A5-A10 were represented by one isolate per profile: $S$. hominis (A5), S. capitis (A6), S. haemolyticus (A7), S. warneri (A8), S. cohnii (A9) and S. schleiferi (A10). The application of the test to identify the field isolates of the present study released the previously mentioned profiles A1-A10 in only 85 out of the 113 isolates (75.2\%), the remaining 28 isolates showed other 27 profiles (Table 2)which could not be assigned to any of the reference strains examined in the present study.

When combining both antibiotic resistance and PCR amplification profiles, a sum of 69 field isolates could be identified. In case of $S$. chromogenes $(\mathrm{n}=3)$ and $S$. hyicus $(n=17)$ revealing the same antibiotic resistance and PCR amplicon profiles, typical cultural morphological properties $^{[24]}$ were additionally used for further differentiation of these two specimens. From the remaining 49 identifiable isolates, 25 could be subscribed as $S$. caprae, both $S$. epidermidis and $S$. simulans could be detected 8 times each. Meanwhile, S. saprophyticus $(\mathrm{n}=4)$, S. lentus $(\mathrm{n}=2)$ and finally both $S$. xylosus and $S$. hominis which could be detected only one time out of the 118 isolates (Table 3 and 4).

It was not possible to understand how the molecular data was combined with antimicrobial susceptibility results to give the final identification of the 69 isolates. For example: in the profile A1 there were the following species: S. chromogenes, S. hyicus, S. epidermidis, S. saprophyticusand $S$. xylosus, sharing the same profile. A total of 45 field isolates showed this pattern (Table 2). In Table 3, only 32 isolates were classified in this profile. S. caprae was detected in 6 herds. S. epidermidis and $S$. chromogenes were detected in one herd, both S. simulans and $S$. hyicus in 3 herds, both $S$. saprophyticus 


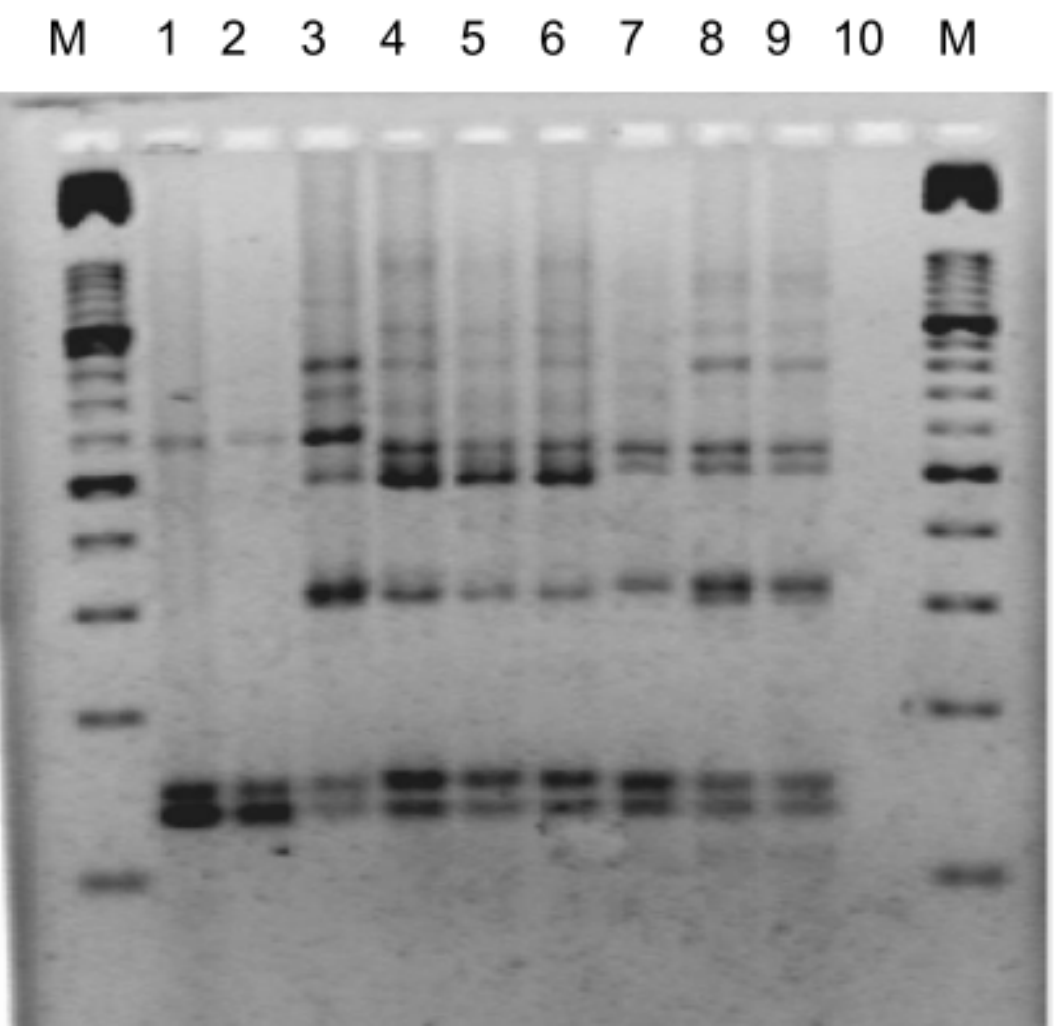

Fig. 1: t-DNA-PCR patterns obtained from reference strains. M. Marker, line 1-3 (S. simulans), line 4-6 (S. xylosus), line 7-9 (S. epidermidis), line 10 (Aqua dest.)

Table 3: The profiles of the 17 different NAS species isolates which were obtained after combining both antibiotic resistance and PCR amplification profiles

\begin{tabular}{|c|c|c|c|c|}
\hline Reference strain & Amplicon profile & Resistance profile & Field isolates (n) & Field isolates (\%) \\
\hline S. chromogenes ${ }^{1)}$ & A1 & $\mathrm{R} 2$ & 3 & 2.5 \\
\hline S. hyicus ${ }^{1)}$ & $\underline{\mathrm{A} 1}$ & $\underline{\mathrm{R} 2}$ & 17 & 14.4 \\
\hline S. epidermidis & $\overline{\mathrm{A} 1}$ & $\overline{\mathrm{R} 5}$ & 8 & 6.8 \\
\hline S. saprophyticus & A1 & R4 & 4 & 3.4 \\
\hline S. xylosus & A1 & R7 & 1 & 0.8 \\
\hline S. caprae & A2 & R1 & 25 & 21.2 \\
\hline S. simulans & A2 & R2 & 8 & 6.8 \\
\hline S. lentus & A3 & R3 & 2 & 1.7 \\
\hline S. sciuri & A3 & R4 & 0 & 0.0 \\
\hline S. auricularis & A4 & R1 & 0 & 0.0 \\
\hline S. lugdunensis & A4 & R2 & 0 & 0.0 \\
\hline S. hominis & A5 & R6 & 1 & 0.8 \\
\hline S. capitis & A6 & R1 & 0 & 0.0 \\
\hline S. haemolyticus & A7 & R1 & 0 & 0.0 \\
\hline S. warneri & A8 & R1 & 0 & 0.0 \\
\hline S. cohnii & A9 & R3 & 0 & 0.0 \\
\hline S. schleiferi & A10 & R2 & 0 & 0.0 \\
\hline
\end{tabular}

*S. chromogenes $(\mathrm{n}=3)$ and $S$. hyicus $(\mathrm{n}=17)$ revealed the same antibiotic resistance and PCR amplicon profiles. Because the reference strains of S. chromogenes and S. hyicus had the same amplicon and resistance profile, typical cultural morphological properties were used for further differentiation

and S. lentus in 2 herds. S. hominis and S. xylosus were detected once. In the present study, $17.3 \%$ of the whole collected samples showed positive bacterial growth which is the identical value stated in Swiss goat herds (17.3\%) according to Schaeren and Maurer. Bacteriological examination of the grown colonies detected NAS in $10.4 \%$ of the samples versus $0.7 \%$ S. aureus. A good udder health in goats with a low frequency of NAS and a very low incidence of S. aureusinfections was already observed in previous studies in the region studied here. Moreover, it was also reported, that in last few years, NAS replaced coagulase positive Staphylococci as a major mastitis the region studied here. Moreover, it was also reported, that in last few 
J. Anim. Vet. Adv., 19 (1): 1-10, 2020

Table 4: The combination of both PCR amplification and resistance profiles of the 44 unidentified field isolates ${ }^{1)}$

\begin{tabular}{|c|c|c|c|c|c|c|c|}
\hline PCR profile & Resistance profile & $\mathrm{n}$ & (\%) & PCR profile & Resistance profile & $\mathrm{n}$ & $(\%)$ \\
\hline A1 & $\mathrm{R} 1$ & 2 & 1.7 & A20 & $\mathrm{R} 1$ & 1 & 0.8 \\
\hline A1 & R3 & 1 & 0.8 & A21 & R1 & 1 & 0.8 \\
\hline $\mathrm{A} 1$ & R6 & 1 & 0.8 & A22 & R3 & 1 & 0.8 \\
\hline A1 & R8 & 3 & 2.5 & A23 & R2 & 1 & 0.8 \\
\hline A1 & R9 & 3 & 2.5 & A24 & R1 & 1 & 0.8 \\
\hline A1 & R11 & 1 & 0.8 & A25 & R1 & 1 & 0.8 \\
\hline A1 & R12 & 1 & 0.8 & A26 & R5 & 1 & 0.8 \\
\hline A2 & R8 & 3 & 2.5 & A27 & R5 & 1 & 0.8 \\
\hline A2 & R11 & 1 & 0.8 & A28 & R4 & 1 & 0.8 \\
\hline A11 & R9 & 2 & 1.7 & A29 & R9 & 1 & 0.8 \\
\hline A12 & R4 & 1 & 0.8 & A30 & R1 & 1 & 0.8 \\
\hline A13 & R2 & 1 & 0.8 & A31 & R1 & 1 & 0.8 \\
\hline A14 & R9 & 1 & 0.8 & A32 & R2 & 1 & 0.8 \\
\hline A15 & R8 & 1 & 0.8 & A33 & R4 & 1 & 0.8 \\
\hline A16 & R2 & 1 & 0.8 & A34 & R2 & 1 & 0.8 \\
\hline A17 & R9 & 1 & 0.8 & A35 & R2 & 1 & 0.8 \\
\hline A18 & R8 & 1 & 0.8 & A36 & R8 & 1 & 0.8 \\
\hline A19 & R1 & 1 & 0.8 & A37 & R3 & 1 & 0.8 \\
\hline
\end{tabular}

${ }^{11}$ In addition to these 44 isolates, additional 69 identifiable field strains are listed in Table 3 (total isolates 118 strains). Five isolates reacted negatively with the PCR and therefore were excluded from both tables (Table 3 and 4). These five isolated showed the antibiotic resistance profile R10 ( $=4$ ) and R13 $(n=1)$ and were addressed to be Micrococci

years, NAS replaced coagulase positive Staphylococci as a major mastitis pathogen in goats in many countries worldwide ${ }^{[16,30]}$. This may be attributed to many factors such as the vaccinal stress due to the use of anti S. aureus mastitis vaccines which could restrict the ability of the S. aureus strains to multiply and spread ${ }^{[31,32]}$.

According to the present work, $60 \%$ of isolated pathogens from mastitic German goat milk samples belonged to one of NAS species. This ratio is similar to that reported in USA in which the NAS prevalence in goat mastitis ranged between 63.5 and $75 \%$ as reported by Tomita et al. ${ }^{[33]}$ and Gaucher, etc., respectively. However, in opposite to the situation in USA and our findings, NAS could be isolated from up to $95.9 \%$ of mastitic goat cases and even from $46.4 \%$ of healthy udder tissues in Italy $^{[8,16]}$.

One of the main mastitis diagnostic tools is the evaluation of SCC. In the present study, the highest achieved geometric mean of SCC values was detected in milk of udders when $S$. aureus was present. The second highest SCC value was recorded in samples of udder halves infected with esculin positive Streptococci. These were followed by samples containing NAS isolates and finally those harbouring Corynebacterium spp. These findings are expected as $S$. aureus strains might harbor more virulence factors than NAS. S. aureus induces the clinical form of mastitis accompanied by clinical symptom of inflammation of the udder tissues. These findings are supported by the data published by Koop et al..$^{[18]}$ and Duralioglu et al. ${ }^{[13]}$.

The present work aimed to identify the NAS at their species level due to their important role as an emerging pathogen in the induction of goat mastitis. To achieve this goal many methods were described in literature. One of the most commonly applied tool in routine diagnostic is the use of commercial biochemical identification assays such as the ID32 staph test ${ }^{[19-21,23,4]}$.

Generally, the commercial tests deliver accurate identification power for the characterization of $S$. aureus isolates ${ }^{[27]}$. However, according to the present findings, their application to identify NAS isolates could only identify $64.7 \%$ of the references trains and $11.4 \%$ of the selected NAS field isolates. It seems that such systems are not accurate enough for the identification of NAS species related to goat mastitis. Ehrenberg reported many cases of confusing identification of NAS species when using different commercial biochemical assays, e.g., a novobiocin sensitive NAS isolate was identified as S. warneri by ID32 STAPH-System and as S. xylosus when using the API-STAPH IDENT-System. For their use in NAS diagnosis in goat milk samples, they may need revalidation. Similar conclusion was also obtained by Sampimon et al. ${ }^{[24]}$.

The use of antibiotic susceptibility pattern analysis for the identification of NAS species was recommended either alone ${ }^{[22,29]}$ in combination with some biochemical reactions ${ }^{[35,36]}$ or in combination with biofilm formation assay $^{[37]}$. For this purpose, the sensitivity of the control NAS strains against novobiocin, desferioxamin, fosfomycin, polymyxin $b$ and furazolidon was tested to be compared later with the resistance profiles of the 118 investigated field isolates. The selected 17 references trains of the present study released only 7 profiles. That means that not all of the included reference strains could certainly be distinguished. Out of the 118 field strains 93 of them could be assigned to these 7 susceptibility patterns. The remaining 25 filed isolates presented six unknown profiles not represented by the reference strains used in this study. Two of them, representing altogether 
five isolates contained furazolidone resistance and therefore were addressed as Micrococci. Although, the antibiotic resistance assay was used in many research papers to identify the NAS at their species level, the use of this assay proved to be insufficient even for the complete differentiation of the 17 reference strains selected in the present study. The reason could be the continuous interaction among the pathogens. Bacterial evolution and the acquisition of new resistance genes may lead to dubious results ${ }^{[38]}$. This might also be the reason for the failure of the antibiotic resistance assay to identify 25 field isolates in the present work. It could also be possible that these unidentified isolates belong to other NAS species rather than those involved in the present investigation. In conclusion, the use of the antibiotic resistance profile should be combined with other identification assays to avoid false results and to improve the rate of identification.

The application of the tDNA-ILP PCR assay using the reference strains involved in the present study lead altogether to 10 amplification patterns. Eighty-five out of 118 field isolates $(75.2 \%)$ could be clearly assigned to these 10 pattern. While no amplification could be seen in five isolates which has been addressed to be Micrococci in the former investigation of the antibiotic sensitivity test as being furazolidone resistant, the remaining 28 field-isolates (24,8\%) delivered atypical profiles which could not be categorized. This may deal with other NAS species which are not involved in this work or may be attributed to genomic dynamism through the acquisition or loss of mobile genetic elements or genomic recombinations.

The combination of various phenotypic and genotypic assays in order to accurately identify the NAS isolates at their species level was also recommended by Widerstrom $^{[39]}$. In the present work, combining the various data delivered from the characterization of the 17 reference strains through tDNA-ILP PCR assay, antibiotic resistance test, culture morphology enabled the identification of 69 out of the 118 field isolates (58.5\%). The isolates could be arranged in 9 different NAS species. The detected 9 different NAS species in the present work were $S$. caprae $(\mathrm{n}=25)$, S. hyicus $(\mathrm{n}=17)$, S. epidermidis $(\mathrm{n}=8)$, S. simulans $(\mathrm{n}=8)$, S. saprophyticus $(\mathrm{n}=4)$, S. chromogenes $(\mathrm{n}=3)$, S. lentus $(\mathrm{n}=2)$, S. xylosus $(\mathrm{n}=1)$ and $S$. hominis $(\mathrm{n}=1)$. These findings are in agreement with the published data dealing with the occurrence of different NAS species by Aulrich and Barth $^{[3]}$, Koop et al. ${ }^{[23]}$ and Rashid et al. ${ }^{[10]}$ who listed S. caprae, S. simulans, S. auricularisand S. hyicusas major mastitis pathogens in goats.

Although, S. caprae seems to be the major NAS species detectable in goat milk as reported here or recommended in earlier studies ${ }^{[12,3]}$. It is interesting to note that $S$. caprae from goat milk was not reported in older research papers as Orden et al. ${ }^{[40]}$ and Maisi and
Riipinen $^{[41]}$ and Winter or was not among the most commonly isolated NAS species ${ }^{[42]}$. This may be due to its minor role in the induction of mastitis previously, different geographic distribution or due to the inaccurate diagnostic tools used previously as the researchers depended on the application of API-staph-system or other biochemical test systems alone which also in the present work was shown to be insufficient to be used for NAS diagnosis at their species level. In the present study other NAS members were also detected such as $S$. hyicus which was isolated 17 times, 12 of them from the same goat indicating a chronic subclinical mastitis possibly caused by an identical field-strain. The presence of S. hyicus in mastitic goat milk was previously already documented ${ }^{[3]}$. Meanwhile, S. epidermidis, S. simulans, S. saprophyticus and $S$. chromogenes could also be detected with a lower prevalence. The presence of these species in goat milk was reported more frequently in the past ${ }^{[42,41,17]}$. However, it seems that they lost their position as major NAS mastitis pathogens for the favour of other members of the NAS family. In addition to the detection in pure culture, the increased occurrence within a herd and the elevation of the cell count, especially, a significant difference between the two udder halves, the repeated detection of a NAS species in the same udder half is considered as another key criterion of possible pathogenicity of a NAS-isolate.

It is noteworthy that in the neibougher country (Swiss) and in opposite to our results, Kunz et al. ${ }^{[43]}$ could not isolate $S$. caprae or $S$. hyicus from mastitic goats. But instead, he isolated both $S$. capitis and $S$. haemolyticus from investigated field samples. Among the most commonly isolated species in Swiss $S$. saprophyticus and $S$. lentuswere reported while $S$. simulans was detected only sporadically Kunz et al. ${ }^{[43]}$. From the epidemiological point of view, S. caprae was the mostly spread NAS species among the investigated herds (6 herds) in the present study which indicates its epidemiological role in mastitis induction in goats in the investigated area.This was followed by both S.simulans and S. hyicus (3 herds) and S. saprophyticus and S. lentus in 2 herds. In opposite to S. epidermidis, S. chromogenes, $S$. hominis and $S$. xylosus which seem to be only sporadic mastitis inducers and could be detected only in one herd.

Other NAS species recorded to induce mastitis in goats from other authors could not be isolated in the present study including $S$. capitis, S. haemolyticus, S. warneri $^{[43,4]}$ S. lugdunensis, S. saprophyticus, $S$. hominis, S. cohnii ${ }^{[14]}$, S. auricularis. In addition $S$. sciuri which mainly is described as being a pig pathogen ${ }^{[44]}$ but was accidentally isolated from goat mastitis in $1984^{[42]}$. This may attributed to their geographical distribution or possibly the presence of one or more of these species among the unidentifiable NAS group in this research. 


\section{CONCLUSION}

In the present research, different NAS field isolates originating from caprine mastitis could be characterized at their species level. Whereas S. caprae, S. epidermidis, S. simulans, S. hyicus, S. saprophyticus, S. chromogenes, $S$. lentus, $S$. xylosus and $S$. hominiscould be isolated. The most predominant species was $S$. caprae while $S$. lentus, $S$. xylosus and $S$. hominiscould only be isolated from sporadic cases. And seem to play a negligible role in the induction of caprine mastitis. These epidemiological data are important due to the growing role of NAS in the induction of mastitis and also due to the zoonotical public health importance of some NAS members. Regular monitoring of the filed isolates among dairy animals provides an important overview for the prevalence of mastitis, inducing pathogens and evaluates the progress of mastitis control programs.

\section{ACKNOWLEDGEMENTS}

This research is dedicated to Prof. Dr. rer.nat. Hubertus Brunn, the former director of the Hessian State Laboratory, who went into well-deserved retirement after nearly 40 years of successful work on 31.10.2018.

\section{REFERENCES}

01. El-Sayed, A., W. Awad, N.E. Abdou and H.C. Vazquez, 2017. Molecular biological tools applied for identification of mastitis causing pathogens. Int. J. Vet. Sci. Med., 5: 89-97.

02. Plummer, P. and C. Plummer, 2012. Diseases of the Mammary Gland. In: Sheep and Goat Medicine, Pugh, D.G. and A.N. Baird (Eds.). Elsevier Inc., Amsterdam, Netherlands, ISBN: 9781437723540, pp: 442-465.

03. Aulrich, K. and K. Barth, 2008. Intramammary infections caused by coagulase-negative staphylococci and the effect on somatic cell counts in dairy goats. Landbauforschung Volkenrode, 58: 59-64.

04. Dogruer, G., M. Saribay, O. Aslantas, E. Kirecci, Y. Ergun, A. Ulku and C. Demir, 2016. The prevalance, etiology and antimicrobial susceptibility of the microorganisms in subclinical mastitis in goats. Ataturk Univ. Vet. Bil. Der., 11: 20-24.

05. Dore, S., M. Liciardi, S. Amatiste, S. Bergagna and G. Bolzoni et al., 2016. Survey on small ruminant bacterial mastitis in Italy, 2013-2014. Small Ruminant Res., 141: 91-93.

06. Bexiga, R., M.T. Koskinen, J. Holopainen, C. Carneiro, H. Pereira, K.A. Ellis and C.L. Vilela, 2011. Diagnosis of intramammary infection in samples yielding negative results or minor pathogens in conventional bacterial culturing. J. Dairy Res., 78: 49-55.
07. Nobrega, D.B., J.D. Buck and H.W. Barkema, 2018. Antimicrobial resistance in non-aureus staphylococci isolated from milk is associated with systemic but not intramammary administration of antimicrobials in dairy cattle. J. Dairy Sci., 101: 7425-7436.

08. Virdis, S., C. Scarano, F. Cossu, V. Spanu, C. Spanu and E.P.L. de Santis, 2010. Antibiotic resistance in Staphylococcus aureus and coagulase negative staphylococci isolated from goats with subclinical mastitis. Vet. Med. Int., 10.4061/2010/517060

09. Mugabe, W., S.J. Nsoso, G.S. Mpapho, J.M. Kamau and W. Mahabile et al., 2017. Occurrence of caprine mastitis and its etiological agents and associated selected risk in mid lactating goats in the Oodi extension area of Kgatleng district, Botswana. Acad. Web J. Agric. Res., 2: 14-20.

10. Gelasakis, A.I., A.S. Angelidis, R. Giannakou, G. Filioussis, M.S. Kalamaki and G. Arsenos, 2016. Bacterial subclinical mastitis and its effect on milk yield in low-input dairy goat herds. J. Dairy Sci., 99: 3698-3708.

11. Bergonier, D., R. de Cremoux, R. Rupp, G. Lagriffoul and X. Berthelot, 2003. Mastitis of dairy small ruminants. Vet. Res., 34: 689-716.

12. Moroni, P., G. Pisoni, M. Antonini, G. Ruffo, S. Carli, G. Varisco and P. Boettcher, 2005. Subclinical mastitis and antimicrobial susceptibility of Staphylococcus caprae and Staphylococcus epidermidis isolated from two Italian goat herds. J. Dairy Sci., 88: 1694-1704.

13. Duralioglu, A., A. Bastan, S. Salar, M. Cengiz and M. Akan, 2014. The effects of pre-milking and post-milking teat disinfection in goats on udder health and milk quality. Ankara Univ. Vet. Fak. Derg., 61: 107-110.

14. El-Jakee, J.K., N.E. Aref, A. Gomaa, M.D. El-Hariri, H.M. Galal, S.A. Omar and A. Samir, 2013. Emerging of coagulase negative staphylococci as a cause of mastitis in dairy animals: An environmental hazard. Int. J. Vet. Sci. Med., 1: 74-78.

15. Rashid, M., M.I. Saleem, F. Deeba, M.S. Khan, S.A. Mahfooz, A.A. Butt and M.W. Abbas, 2017. Effect of season on occurrence of caprine mastitis in beetal in faisalabad premises. Matrix Sci. Med., 1: 19-21.

16. Spuria, L., E. Biasibetti, D. Bisanzio, I. Biasato and D.D. Meneghi et al., 2017. Microbial agents in macroscopically healthy mammary gland tissues of small ruminants. Peer J., Vol. 5, 10.7717/peerj.3994

17. Deinhofer, M. and A. Pernthaner, 1995. Staphylococcus spp as mastitis-related pathogens in goat milk. Vet. Microbiol., 43: 161-166. 
18. Koop, G., S. De Vliegher, A. De Visscher, K. Supre, F. Haesebrouck, M. Nielen and T. van Werven, 2012a. Differences between coagulase-negative staphylococcus species in persistence and in effect on somatic cell count and milk yield in dairy goats. J. Dairy Sci., 95: 5075-5084.

19. Chesneau, O., S. Aubert, A. Morvan, J.L. Guesdon and N. El Solh, 1992. Usefulness of the ID32 staph system and a method based on rRNA gene restriction site polymorphism analysis for species and subspecies identification of staphylococcal clinical isolates. J. Clin. Microbiol., 30: 2346-2352.

20. Layer, F., B. Ghebremedhin, K.A. Moder, W. Konig and B. Konig, 2006. Comparative study using various methods for identification of Staphylococcus species in clinical specimens. J. Clin. Microbiol., 44: 2824-2830.

21. Babu, E. and J. Oropello, 2011. Staphylococcus lugdunensis: The coagulase-negative staphylococcus you don't want to ignore. Expert Rev. Anti-Infective Therapy, 9: 901-907.

22. Jarlov, J.O., 1999. Phenotypic characteristics of coagulase-negative staphylococci: Typing and antibiotic susceptibility. APMIS. Suppl., 91: 1-42.

23. Koop, G., A.D. Visscher, C.A. Collar, D.A.C. Bacon and E.A. Maga et al., 2012b. Identification of coagulase-negative staphylococcus species from goat milk with the API Staph identification test and with transfer RNA-intergenic spacer PCR combined with capillary electrophoresis. J. Dairy Sci., 95: 7200-7205.

24. Foster, T., 1996. Staphylococcus. In: Medical Microbiology, Baron, S. (Ed.). University of Texas Medical Branch, Texas, USA., pp: 187-197.

25. Maes, N., Y.D. Gheldre, R.D. Ryck, M. Vaneechoutte, H. Meugnier, J. Etienne and M.J. Struelens, 1997. Rapid and accurate identification of Staphylococcus species by tRNA intergenic spacer length polymorphism analysis. J. Clin. Microbiol., 35: 2477-2481.

26. Gheldre, Y.D., N. Maes, F.L. Presti, J. Etienne and M. Struelens, 2001. Rapid Identification of clinically relevant Legionella spp. by analysis of transfer DNA intergenic spacer length polymorphism. J. Clin. Microbiol., 39: 162-169.

27. Reinoso, E.B., A. El-Sayed, C. Lammler, C. Bogni and M. Zschock, 2008. Genotyping of Staphylococcus aureus isolated from humans, bovine subclinical mastitis and food samples in Argentina. Microbiol. Res., 163: 314-322.

28. Rheinbaben, K.E.V. and R.M. Hadlok, 1981. Rapid distinction between micrococci and staphylococci with furazolidone agars. Antonie Van Leeuwenhoek, 47: 41-51.
29. Devriese, L.A., H. Laevens, F. Haesebrouck and J. Hommez, 1994. A simple identification scheme for coagulase negative staphylococci from bovine mastitis. Res. Vet. Sci., 57: 240-244.

30. Kautz, F.M., S.C. Nickerson and L.O. Ely, 2014. Use of a staphylococcal vaccine to reduce prevalence of mastitis and lower somatic cell counts in a registered Saanen dairy goat herd. Res. Vet. Sci., 97: 18-19.

31. Schukken, Y.H., V. Bronzo, C. Locatelli, C. Pollera and N. Rota et al., 2014. Efficacy of vaccination on Staphylococcus aureus and coagulase-negative staphylococci intramammary infection dynamics in 2 dairy herds. J. Dairy Sci., 97: 5250-5264.

32. Landin, H., M.J. Mork, M. Larsson and K.P. Waller, 2015. Vaccination against Staphylococcus aureus mastitis in two Swedish dairy herds. Acta Vet. Scand., Vol. 57, 10.1186/s13028-015-0171-6

33. Tomita, G., B. Min, S. Hart and M. Paape, 2003. Effect of Staphylococcal intramammary infection on milk composition of goats. Proceedings of the 42nd National Annual Meeting on Mastitis Council, January 26-29, 2003, Ars Publications, Chennai, India, pp: 1-32.

34. Sampimon, O.C., R.N. Zadoks, S. De Vliegher, K. Supre and F. Haesebrouck et al., 2009. Performance of API Staph ID 32 and Staph-Zym for identification of coagulase-negative staphylococci isolated from bovine milk samples. Vet. Microbiol., 136: 300-305.

35. Iorio, N.L.P., R.B.R. Ferreira, R.P. Schuenck, K.L. Malvar and A.P. Brilhante et al., 2007. Simplified and reliable scheme for species-level identification of Staphylococcus clinical isolates. J. Clin. Microbiol., 45: 2564-2569.

36. Becker, K., C. Heilmann and G. Peters, 2014. Coagulase-negative staphylococci. Clin. Microbiol. Rev., 27: 870-926.

37. Shrestha, L.B., N.R. Bhattarai and B. Khanal, 2017. Antibiotic resistance and biofilm formation among coagulase-negative Staphylococci isolated from clinical samples at a tertiary care hospital of Eastern Nepal. Antimicrob. Resist. Infect. Contr., Vol. 6, 10.1186/s13756-017-0251-7

38. Nichol, D., J. Rutter, C. Bryant, A.M. Hujer and S. Lek et al., 2019. Antibiotic collateral sensitivity is contingent on the repeatability of evolution. Nat. Commun., Vol. 10, 10.1038/s41467-018-08098-6

39. Widerstrom, M., 2010. Molecular epidemiology of coagulase-negative staphylococci in hospitals and in the community. M.Sc. Thesis, Department of Clinical Microbiology, Clinical Bacteriology and Infectious Diseases, Umea University, Umea, Sweden. 
40. Orden, J.A., J. Goyache, J. Hernandez, A. Domenech, G. Suarez and E. Gomez-Lucia, 1992. Production of staphylococcal enterotoxins and TSST 1 by coagulase negative Staphylococci isolated from ruminant mastitis. J. Vet. Med., 39: 144-148.

41. Maisi, P. and I. Riipinen, 1991. Pathogenicity of different species of staphylococci in caprine udder. Br. Vet. J., 147: 126-132.

42. Poutrel, B., 1984. Staphylococcus sciuri subsp lentus associated with goat mastitis. Am. J. Vet. Res., 45: 2084-2085.
43. Kunz, F., S. Corti, N. Giezendanner, R. Stephan, M. Wittenbrink and C. Zweifel, 2011. Antimicrobial resistance of Staphylococcus aureus and coagulase negative staphylococci isolated from mastitis milk samples from sheep and goats. Schweizer Arch. Tierheilkunde, 153: 63-69.

44. Chen, S., Y. Wang, F. Chen, H. Yang, M. Gan and S.J. Zheng, 2007. A highly pathogenic strain of Staphylococcus sciuri caused fatal exudative epidermitis in piglets. PLoS ONE, Vol. 2, No. 1 10.1371/journal.pone.0000147 